Bangladesh J. Bot. 38(2): 119-125, 2009 (December)

\title{
DIVERSITY AND PATHOGENICITY OF THE RICE BROWN SPOT PATHOGEN, BIPOLARIS ORYZAE (BREDA DE HAAN) SHOEM. IN BANGLADESH ASSESSED BY GENETIC FINGERPRINT ANALYSIS
}

\author{
M. M. KAMAL ${ }^{1}$ AND M. A. T. Mia \\ Seed Pathology and Molecular Laboratory, Plant Pathology Division \\ Bangladesh Rice Research Institute, Gazipur-1701, Bangladesh
}

Key words: Bipolaris oryzae, Rice brown spot, Pathogenicity, Agarose-synergel, Fingerprints

\begin{abstract}
A survey on the occurrence of rice brown spot pathogen, Bipolaris oryzae (Breda de Haan) Shoem. was carried out across Bangladesh. A representative set of 152 isolates were characterized based on DNA fingerprinting, using variable number tandem repeat analysis and assessed their phylogenetic identity, diversity and pathogenicity. The analysis showed considerable diversity among the isolates, being separated into 12 fingerprint types at 75\% similarity level. Majority of the samples possessed one fingerprint type. Pathogenicity test with nine fingerprint types on rice variety BR24, showed 20.5-84.5\% germination failure, 2.50-12.50, 5.84-11.67 and 7.50-14.17\% post-emergence seedling death at 15, 30 and 45 days after transplanting and $18.75-22.50 \%$ yield loss. Significant differences in aggressiveness were observed among the isolates of the same fingerprint types.
\end{abstract}

\section{Introduction}

Rice brown spot pathogen, Bipolaris oryzae (Breda de Haan) Shoem. is predominant in Bangladesh (Mia 2004). The pathogen is responsible for germination failure, rotting of seeds, roots and coleoptiles, poor germination and poor seedling vigour (Mia and Nahar 2001, Naeem et al. 2001, Malavolta et al. 2002). The disease is severe where plants are grown under stress conditions causing appreciable yield loss.

In Bangladesh where rice is grown in overlapping seasons, $B$. oryzae spreads from one field to another through living plant parts. Varietal resistance to brown spot occurs in rice but quantitative and clear physiological races of the pathogen that express cultivar specificity, is not evident (Malavolta et al. 2002, Thuy 2002). Different strains do, however, appear to have different levels of aggressiveness (Thuy 2002, Kamal 2006). Little is known about the diversity and pathogenicity of $B$. oryzae strains in Bangladesh. The present work was undertaken to characterize the fungus following DNA fingerprinting, determine their biological variation, record their diversity and determine the variation in their pathogenicity.

\section{Materials and Methods}

Isolation and purification: The pathogen, Bipolaris oryzae (Breda de Haan) Shoem. was isolated by tissue planting method and purified through transfer of single conidium to potato dextrose agar (PDA) medium. The fungus was grown in potato dextrose broth for three days, mycelia were harvested and blotted to remove excess fluid and stored at $-20^{\circ} \mathrm{C}$ in aluminium foil packet. DNA was extracted from 306 isolates including 2 isolates of IRRI following Raeder and Broda (1985) and Anonymous (2001). DNA concentration was estimated on 0.8\% agarose gel and $1 \mathrm{ng} / \mu \mathrm{l}$ stocks were prepared for variable number tandem repeat-polymerase chain reaction (VNTR-PCR, Pascual et al. 2000).

\footnotetext{
${ }^{1}$ Corresponsing author: Plant Pathology Division, BRRI Regional Station, Barisal, Bangladesh.
} 
Agarose-synergel electrophoresis for VNTR analysis: Based on the morphology of the fungus, 152 isolates were selected for VNTR-PCR. An amount of 1ng of fungal DNA was amplified with primer MR (GAGGGTGGCGGTTCT) under the conditions: $94^{\circ} \mathrm{C}$ for 2 minutes, then 35 cycles of $94^{\circ} \mathrm{C}$ for 20 seconds, $45^{\circ} \mathrm{C}$ for 30 seconds and finally $72^{\circ} \mathrm{C}$ for 2.5 minutes. This was followed by 5 minutes at $72^{\circ} \mathrm{C}$ and then held at $4^{\circ} \mathrm{C}$ until the sample was retrieved. The Primer MR was used following Bridge et al. (1997). Amplified DNA of 152 isolates and 1kb ladder was loaded into the gel and resolved by electrophoresis for 7 hours at 100 millivolts. The gel was stained and the fingerprints photographed. DNA fingerprints were scored visually and recorded according to the position of bands for each of the 152 isolates as 1 , for the presence and 0 , for the absence of a band. A similarity matrix based on Jaccard's similarity coefficient was used and cluster analysis of the matrix was done using unweighted pair group method with arithmetic mean (UPGMA) by numerical taxonomy and multivariate analysis system (NTSYS-PC) version 2.11a (Rohlf 2000).

Pathogenicity of Bipolaris oryzae: The effects of Bipolaris oryzae, on seed infection, pre- and post-emergence death of seedlings and subsequent disease development in plants were investigated. The soil was fertilized with $60 \mathrm{~kg} \mathrm{~N}+35 \mathrm{~kg} \mathrm{P}+40 \mathrm{~kg} \mathrm{~K} / \mathrm{ha}$. Hot water treated truthfully labelled seeds (TLS) were placed on two days old cultures of B. oryzae, representing nine fingerprint types (FPTs) keeping necessary control and observed for 5-7 days and percentage of germination was recorded. Eight replications for each isolate were maintained in completely randomized design (CRD). In a glasshouse, 30 germinated seeds for each replication/isolate were sown in each tray of sterilized soil and the trays were arranged in CRD with four replications. Necessary cultural practices were done as and when needed. Post-emergence death of the seedlings was recorded at 15 days after transplanting (DAT), 30 DAT and 45 DAT. Another set of inoculated and un-inoculated seeds were directly sown in a $1 \mathrm{x} 1 \mathrm{~m}$ plots with spacing of $20 \mathrm{x} 15$ $\mathrm{cm}$ following CRD with five replications. Number of effective tillers at maturity from each treatment was counted and grain yield was calculated.

\section{Results and Discussion}

Characterized B. oryzae are shown in Table 1 and Fig. 1. These revealed a good number of very distinct DNA fingerprints and considerable polymorphism among the 152 isolates. At $75 \%$ similarity level, the isolates were placed under 12 FPTs (Fig. 1). The largest group was FPT 10 with 53 isolates represented in all the regions and covered about $35 \%$ of the total isolates studied.

Table 1. Fingerprint types of 152 Bipolaris oryzae isolates at 75\% similarity by VNTR-PCR.

\begin{tabular}{llllllllllllll}
\hline Site/FPT & 1 & 2 & 3 & 4 & 5 & 6 & 7 & 8 & 9 & 10 & 11 & 12 & Total \\
\hline Chuadanga & 1 & - & - & - & - & - & - & 1 & 1 & 13 & - & 6 & 22 \\
Gazipur & 2 & - & - & - & - & - & 10 & 2 & 4 & 2 & - & - & 20 \\
Habiganj & - & - & - & - & - & - & 8 & - & - & 11 & 2 & - & 21 \\
Barisal & & - & 3 & 3 & - & 4 & 3 & - & 2 & 16 & - & - & 31 \\
Rangpur & 2 & 1 & - & - & - & - & 3 & - & 1 & 7 & 4 & - & 18 \\
Rajshahi & 1 & 11 & - & - & 1 & 1 & 4 & - & - & 2 & 4 & - & 24 \\
Bogra & - & 9 & - & - & - & - & 3 & - & - & 2 & - & - & 14 \\
IRRI & - & 2 & - & - & - & - & - & - & - & - & - & - & 2 \\
Total & 6 & 23 & 3 & 3 & 1 & 5 & 31 & 3 & 8 & 53 & 10 & 6 & 152 \\
$\%$ & 3.95 & 15.13 & 1.97 & 1.97 & 0.66 & 3.29 & 20.39 & 1.97 & 5.26 & 34.87 & 6.58 & 3.95 & 100 \\
\hline
\end{tabular}




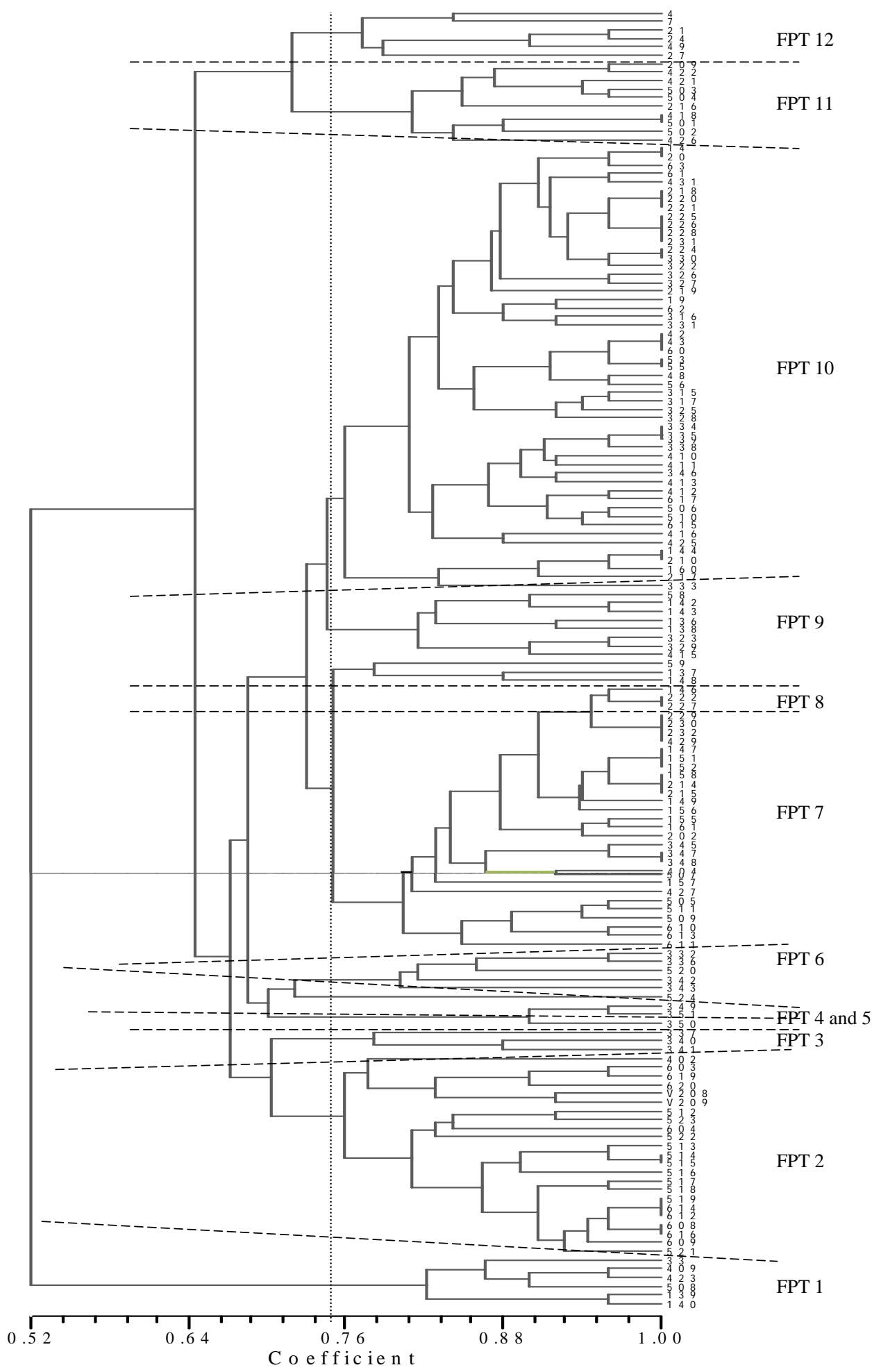

Fig. 1. The dendogram of 152 Bipolaris oryzae (Breda de Haan) Shoem. isolates assessed by VNTR-PCR. 
The second largest group was FPT 7 comprised of 31 isolates, which represented all the regions except Chuadanga and covered $20 \%$ of the total isolates. The third largest group was FPT 2 comprised of 23 isolates and that represented the isolates of Rangpur, Rajshahi and Bogra regions and IRRI that covered $15 \%$ of the total isolates. The results showed that the largest three groups FPT 10, 7 and 2 covered about 58\% of the total isolates.

Many individuals within these finger print types could also be distinguished. Clear polymorphic differences between Bangladeshi and non-Bangladeshi isolates were noticed even at above $80 \%$ similarity level (Fig. 1). The presence of such very widespread FPTs was also observed in Bipolaris oryzae of Vietnam (Thuy 2002) and in Rhizoctonia solani (Ali 2002, Ali et al. 2004) of Bangladesh.

Hydrologically, every year Bangladesh receives huge amount of floodwater from India. There is a possibility that floodwater carry floating propagules of Bipolaris oryzae-infected plant parts perhaps introducing the fungal isolates genetically distinct from those indigenous types. Another possibility is germplasm exchange and/or import of contaminated seeds (Ali 2002, Ali et al. 2004) for Rhizoctonia solani. It is noted that isolates from neighbouring locations were placed in a major fingerprint type indicating that these isolates may have the same origin. During the post-flood rehabilitation, exchange of rice seeds and seedlings from flood free areas is a common practice, therefore long distance (regional) spread through infected rice seeds and seedlings is not unlikely.

The germination test revealed that the reduction in germination ranged from 20.5-84.5\% (Table 2). The isolate BO202 caused the highest germination failure (84.5\%) followed by isolates BO616 (82.5\%) and BO617 (81.0\%). The isolate BO019 caused the lowest (20.5\%) germination failure. Variation in germination failure was also noted among the isolates of Bipolaris oryzae by Singh et al. (1979), Zulkifli et al. (1991) and Mia et al. (2001) who found $11-29 \%, 40 \%$ and 15.9 $19.0 \%$ germination failure, respectively.

The results of post-emergence seedling deaths showed that the isolate BO202 caused the highest death followed by the isolate BO616 at 15 DAT, but at 30 DAT and 45 DAT it was same for both the isolates (Table 2). The isolate $\mathrm{BO} 202$ also caused the highest germination failure of the seed indicating its highest aggressiveness. The isolate BO055 caused the lowest postemergence death of the seedlings at 15, 30 and 45 days after transplanting, indicating its lowest aggressiveness. All the isolates showed higher post-emergence deaths compared to the control. Post-emergence seedling deaths differed from isolate to isolate irrespective of fingerprint types. The results of post-emergence seedling deaths support the findings of Mendoza and Molina (1980) who found $32 \%$ mortality.

The effects of the pathogen on tiller and yield showed that the highest reduction of tiller number was found with the isolate BO202 and that of the lowest with the isolate BO214 (Table 3). It is revealed that the reduction in tiller number ranged from $22.78-32.83 \%$ for different isolates that, supports the findings of Mia et al. (2001) who found 7.6-28.4\% reduction.

The results also showed the highest reduction of yield was caused by the isolates BO202 and BO617 and that of the lowest by the isolate BO332 (Table 3). The results further showed that the reduction in yield ranged from $18.75-22.50 \%$ over control that supports the findings of Vidyasekaran and Ramadoss (1973), Singh et al. (1979) and Mia et al. (2001) who found 20-40\%, $3.7-29.1 \%$ and $9.28-24.50 \%$ yield loss, respectively. 
Table 2. Effect of Bipolaris oryzae on seed germination and death of seedlings of BR24 rice.

\begin{tabular}{lrrrr}
\hline Isolate (FPT) & $\begin{array}{l}\text { Germination } \\
\text { failure (\%) }\end{array}$ & \multicolumn{3}{c}{ Post-emergence seedling death (\%) } \\
\cline { 3 - 5 } & & \multicolumn{1}{c}{$5 \mathrm{DAT}$} & \multicolumn{1}{c}{$30 \mathrm{DAT}$} & $45 \mathrm{DAT}$ \\
\hline BO202 (7) & $84.5 \pm 5.42$ & $12.50 \pm 1.66$ & $11.67 \pm 1.92$ & $14.17 \pm 1.67$ \\
BO616 (2) & $82.5 \pm 2.98$ & $11.67 \pm 1.92$ & $11.67 \pm 1.92$ & $14.17 \pm 1.67$ \\
BO522 (2) & $75.0 \pm 3.55$ & $10.83 \pm 1.67$ & $10.83 \pm 1.67$ & $14.17 \pm 3.19$ \\
BO427 (7) & $73.5 \pm 3.66$ & $10.00 \pm 0.00$ & $10.83 \pm 1.67$ & $11.67 \pm 1.92$ \\
BO615(10) & $75.5 \pm 3.96$ & $9.17 \pm 1.67$ & $10.00 \pm 0.00$ & $12.50 \pm 1.67$ \\
BO617 (10) & $81.0 \pm 5.55$ & $8.34 \pm 1.92$ & $9.17 \pm 1.67$ & $12.50 \pm 1.67$ \\
BO421 (11) & $28.0 \pm 4.78$ & $7.50 \pm 1.67$ & $10.83 \pm 1.67$ & $10.17 \pm 1.67$ \\
BO423(1) & $77.0 \pm 5.95$ & $8.34 \pm 1.92$ & $9.17 \pm 1.67$ & $10.83 \pm 1.67$ \\
BO138 (9) & $81.0 \pm 1.85$ & $7.50 \pm 1.66$ & $10.00 \pm 0.00$ & $10.83 \pm 1.67$ \\
BO021 (12) & $79.0 \pm 2.83$ & $6.67 \pm 0.00$ & $10.83 \pm 1.67$ & $10.83 \pm 1.67$ \\
BO332 (6) & $33.0 \pm 3.55$ & $6.67 \pm 0.00$ & $8.34 \pm 1.92$ & $10.83 \pm 1.67$ \\
BO161 (7) & $71.0 \pm 6.32$ & $7.50 \pm 1.66$ & $9.17 \pm 1.67$ & $10.83 \pm 1.67$ \\
BO517 (2) & $27.5 \pm 5.83$ & $7.50 \pm 1.67$ & $8.34 \pm 1.92$ & $10.00 \pm 0.00$ \\
BO350 (4) & $34.0 \pm 6.41$ & $5.00 \pm 1.93$ & $9.17 \pm 3.19$ & $9.17 \pm 1.67$ \\
BO214 (7) & $27.5 \pm 6.21$ & $5.00 \pm 1.93$ & $9.17 \pm 1.67$ & $9.17 \pm 1.67$ \\
BO136(10) & $22.0 \pm 5.24$ & $4.17 \pm 1.67$ & $9.17 \pm 1.67$ & $9.17 \pm 1.67$ \\
BO019(10) & $20.5 \pm 3.34$ & $4.17 \pm 1.67$ & $8.34 \pm 1.92$ & $10.00 \pm 0.00$ \\
BO063(10) & $29.0 \pm 6.68$ & $5.00 \pm 1.93$ & $7.50 \pm 1.67$ & $9.17 \pm 1.67$ \\
BO315(10) & $25.0 \pm 6.32$ & $4.17 \pm 1.67$ & $7.50 \pm 1.67$ & $8.34 \pm 1.92$ \\
BO055(10) & $21.0 \pm 5.95$ & $2.50 \pm 1.67$ & $5.84 \pm 1.67$ & $7.50 \pm 1.67$ \\
Control & $5.5 \pm 2.07$ & $0.83 \pm 1.67$ & $3.33 \pm 0.00$ & $5.00 \pm 1.93$ \\
\hline
\end{tabular}

There was no obvious correlation between pathogenicity and genetic variation with respect to fingerprint types because there were many clusters among the low number of isolates. However, when comparing the pathogenicity reactions of the isolates, similar patterns were seen for isolates belonging to distantly related clusters, e.g. FPT 1 (BO423) and FPT 12 (BO021), demonstrating lack of relationship between pathogenicity and genetic variation. Thuy (2002) also found a low correlation between pathogenicity and genetic variation in Bipolaris oryzae. In contrast, in the same cluster FPT 10, isolate BO019 showed less aggressiveness than isolate BO617. Levy et al. (1993) also observed multiple pathotypes per lineage for Pyricularia grisea in rice. Taking the preliminary nature of the results into considerations, there could be several reasons for the relatively poor correlation between genotypic variation and pathogenicity. Polymerase chain reaction (PCR) data showed a lot of genetic variation possibly due to the random nature of VNTR distribution in the genome of Bipolaris oryzae.

It was not possible to understand which kind of variation in the PCR results were related to resistance. Nagai and Hara (1930) found resistance as a dominant factor but Adair (1941) concluded that resistance against $B$. oryzae inherited as a recessive trait and one or several genes are involved with it. It appears that isolates are organized, with very aggressive types and less aggressive types in different groups. 
Table 3. Effect of Bipolaris oryzae on number of tillers and yield of BR24 rice.

\begin{tabular}{lll}
\hline Isolate (FPT) & Number of tillers $/ \mathrm{m}^{2}$ & Grain yield (t/ha) \\
\hline BO202 (7) & $125.6 \pm 11.10(32.83)$ & $1.86 \pm 0.11(22.50)$ \\
BO161 (7) & $134.0 \pm 9.92(28.34)$ & $1.87 \pm 0.12(22.08)$ \\
BO427 (7) & $134.4 \pm 10.06(28.13)$ & $1.88 \pm 0.13(21.67)$ \\
BO522 (2) & $127.8 \pm 12.38(31.66)$ & $1.88 \pm 0.13(21.67)$ \\
BO138 (9) & $130.2 \pm 11.12(30.37)$ & $1.90 \pm 0.14(20.83)$ \\
BO423 (1) & $126.4 \pm 10.10(32.40)$ & $1.90 \pm 0.16(20.83)$ \\
BO021 (12) & $127.8 \pm 13.03(31.66)$ & $1.91 \pm 0.11(20.42)$ \\
BO616 (2) & $134.0 \pm 13.87(28.34)$ & $1.91 \pm 0.13(20.42)$ \\
BO617 (10) & $126.4 \pm 10.60(32.40)$ & $1.86 \pm 0.13(22.50)$ \\
BO214 (7) & $144.4 \pm 10.16(22.78)$ & $1.92 \pm 0.13(20.00)$ \\
BO615 (10) & $128.0 \pm 12.19(31.55)$ & $1.92 \pm 0.13(20.00)$ \\
BO517 (2) & $142.0 \pm 10.37(24.06)$ & $1.92 \pm 0.15(20.00)$ \\
BO019 (10) & $144.0 \pm 16.99(22.99)$ & $1.93 \pm 0.11(19.58)$ \\
BO350 (4) & $141.6 \pm 10.31(24.28)$ & $1.93 \pm 0.11(19.58)$ \\
BO063 (10) & $143.6 \pm 9.63(23.20)$ & $1.93 \pm 0.12(19.58)$ \\
BO315 (10) & $143.6 \pm 10.92(23.20)$ & $1.93 \pm 0.13(19.58)$ \\
BO136 (9) & $143.6 \pm 10.01(23.20)$ & $1.94 \pm 0.11(19.17)$ \\
BO055 (10) & $143.2 \pm 14.69(23.42)$ & $1.94 \pm 0.15(19.17)$ \\
BO421 (11) & $143.6 \pm 10.92(23.20)$ & $1.94 \pm 0.15(19.17)$ \\
BO332 (6) & $141.0 \pm 10.65(24.60)$ & $1.95 \pm 0.11(18.75)$ \\
Control & $187.0 \pm 14.39$ & $2.40 \pm 0.16$ \\
\hline
\end{tabular}

Data in parenthesis of column 2 and 3 indicate the percentage of reduction over control.

\section{References}

Adair C.R. 1941. Inheritance in rice of reaction to Helminthosporium oryzae and Cercospora oryzae. Technical Bulletin, United States Department of Agriculture No. 772.18 pp.

Ali M.A. 2002. Biological variation and chemical control of Rhizoctonia solani causing rice sheath blight diseases in Bangladesh. Ph. D. thesis, Univ. London, Imperial College, London. 202 pp.

Ali M.A., M.M. Kamal, S.A. Archer, A. Buddie and M. Rutherford. 2004. Anastomosis and DNA fingerprinting the rice isolates of Rhizoctonia solani Kuhn using AFLP markers. Bangladesh J. Plant Pathol. 20(1-2): 1-8.

Anonymous. 2001. Molecular cloning: a laboratory manual. Sambrook, J. and D.W. Russel (Eds) Vol. I.

Bridge P.D., D.A. Pearce, A. Rivera and M.A. Rutherford. 1997. VNTR-derived oligonucleotides as PCR primers for population studies in filamentous fungi. Letters Appl. Microbiol. 24: 426-430.

Levy M., F.J. Correa-Victoria, R.S. Zeigler, S. Xu and J.E. Hamer. 1993. Genetic diversity of the rice blast fungus in a disease nursery in Colombia. Phytopathology 83: 1427-1433.

Kamal M.M. 2006. Characterization of seed borne Bipolaris oryzae and quantification of its transmission. Ph. D. thesis, Dept. Plant Path., Agric. Univ., Mymensingh. 158 pp.

Malavolta V.M.A., J.J.D. Parisi, H.M. Takada and M.C. Martins. 2002. Effect of different incidence levels of Bipolaris oryzae in rice seeds on physiological aspects: seed-seedling transmission and production. Summa Phytopathologica 28(4): 336-340.

Mendoza A.M. and R.P. Molina. 1980. A study on seed-borne fungi associated with rice seed and their effects on rice seedling. Araneta Res. J. (Philippines) 27(1-4): 50-69. 
Mia M.A.T. 2004. Production, drying and preservation of quality rice seeds at farm level. In: Proceedings Technology Development Workshop, pp. 11-51. Organized by PETRRA-IRRI and BRRI, held in Bangladesh Rice Research Institute, Gazipur.

Mia M.A.T. and M.A. Nahar. 2001. Status of rice seed health in Bangladesh and farmers' seed production and management scenario. In: Seed health and seed associated microorganisms for rice disease management, T.W. Mew and B. Cotyn. (Eds), pp. 81-86. Limited Proceedings No. 6. International Rice Research Institute, Los Banos.

Mia M.A.T., M. Rahman, D. Pearce and M. Holderness. 2001. Effect of seed-borne Bipolaris oryzae on seed germination and disease development in the field. Bangladesh J. Plant Path. 17(1-2): 59-62.

Naeem K., S.A. Anwar, M.I. Haque, A. Riaz and M.S.A. Khan. 2001. Seed-borne fungi and bacteria of rice and their impact on seed germination. Pak. J. Phytopath. 13(1): 75-81.

Nagai I. and S. Hara. 1930. On the inheritance of variegation disease in a strain of rice-plant. Japanese J. Bot. 5: 41.

Pascual C.B., T. Toda, A.D. Raymondo and M. Hyakumachi. 2000. Characterization by conventional techniques and PCR of Rhizoctonia solani isolates causing banded leaf sheath blight in maize. Plant Path. 49: 108-118.

Raeder U. and P. Broda. 1985. Rapid preparation of DNA from filamentous fungi. Letters Appl. Microbiol. 1: 17-20.

Rohlf F.J. 2000. NTSYS-pc. Numerical taxonomy and multivariate system version 2.11a. Exeter Publ., Ltd., Setauket, NY.

Singh R.P., P.N. Singh and P. Shukla. 1979. Note on assessment of losses in rice due to brown leaf spot diseases. Indian J. Agric. Res. 13(1): 57-58.

Thuy T.T.T. 2002. Infection Biology of Bipolaris oryzae in rice and its pathogenic variation in the Mekong Delta, Vietnam. Ph. D. Thesis. Dept. Plant Biol., The Royal Veterinary \& Agric. Univ. Copenhagen. 308 pp.

Vidyasekaran P. and N. Ramadoss. 1973. Quantitative and qualitative losses in paddy due to Helminthosporiose epidemic. Indian Phytopath. 26: 479-484.

Zulkifli E., J. Klap and J. Castano 1991. Effect of grain discoloration in upland rice on some yield components. IRRI News Letter 16(4): 20.

(Manuscript received on 17 September, 2009; revised on 24 June, 2009) 